\title{
Peer-to-peer planning for space mission control
}

\author{
Javier Barreiro \\ SGT Inc. \\ NASA Ames Research Center MS-3 , Moffett Field,CA 94053 \\ javier.barreiro@nasa.gov
}

Grailing Jones Jr, Steve Schaffer

JPL, 4800 Oak Grove Drive, Pasadena, CA 91109

\{grailing.jones-jr, steve.schaffer\}@jpl.nasa.gov

Abstract-Planning and scheduling for space operations entails the development of applications that embed intimate domain knowledge of distinct areas of mission control, while allowing for significant collaboration among them. The separation is useful because of differences in the planning problem, solution methods, and frequencies of replanning that arise in the different disciplines. For example, planning the activities of human spaceflight crews requires some reasoning about all spacecraft resources at timescales of minutes or seconds, and is subject to considerable volatility. Detailed power planning requires managing the complex interplay of power consumption and production,

\section{TABLE OF CONTENTS}

1. INTRODUCTION...............................................................................2

2. CREW PlanNING.........................................................................2

ACTIVITIES AND CONSTRAINTS..................................................3

ACTIVITIES AND CONSTRAINTS..................................................3

ACTIVITIES AND CONSTRAINTS..........................................................3

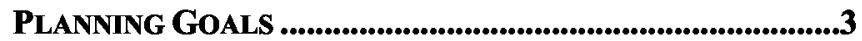

PLANNING GOALS .......................................................................3

PLANNING GOALS .......................................................................3

3. Power Planning...................................................................3

ACTIVITIES AND CONSTRAINTS....................................................4

ACTIVITIES AND CONSTRAINTS.......................................................4

ACTIVITIES AND CONSTRAINTS.............................................4

PLANNING GoALS ..............................................................4

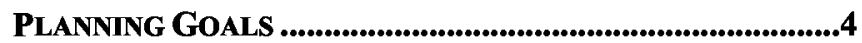

PLANNING GOALS .................................................................

4. INTER-DISCIPLINE INTEGRATION SCENARIO ....................5

5. ARCHITECTURE FOR AN INTEGRATED SOLUTION............5

6. IMPLEMENTATION.........................................................................7

CREW PlanNING APPLICATION....................................................7

CREW PlanNIING APPLICATION..................................................7

CREW PLANNING APPLICATION......................................................

POWER PlanNING APPLICATION...............................................

POWER PlanNING APPLICATION......................................................7

POWER PlanNing APPLICATION..............................................7

7. CONCLUSIONS AND FUTURE DIRECTIONS...........................8

ACKNOWLEDGMENTS .........................................................................8

REFERENCES .......................................................................................8

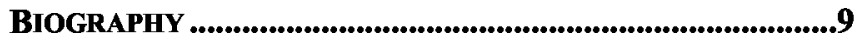

involves very different classes of constraints and preferences, but once plans are generated they are relatively stable. A prototype application has been developed that separately supports Crew planning and Power planning for the International Space Station (ISS). Domain requirements have been modeled in a significant level of detail, and loosely-coupled integration has been demonstrated in a realistic scenario. The integration is enabled by implementing a generic collaboration architecture that can be used to coordinate the work of any number of planning domains. The architecture is used to integrate two different planners employing different underlying algorithms and data structures, by means of mapping the overlapping facets of the plans. 


\section{INTRODUCTION}

AI Planning and Scheduling technology is increasingly being used to support operations in the control center for space missions. A significant technology deployment challenge is in developing domain models and application architectures that naturally map to the processes already established by the mission control organization [1]. Without such arrangement, the technology is unlikely to be adopted. Mission operations planning for the International Space Station (ISS) is a perfect example of this situation; due to the complexity and breadth of the requirements for mission planning, responsibilities are split into a number of flight control disciplines [2] summarized in Figure 1.

Each discipline has very different domain description requirements and spheres of responsibility. At the same time, a large amount of communication among flight controllers is necessary since decisions taken by one discipline may affect one or more of the other disciplines 1 in significant ways. As a simplified example, consider a collision avoidance maneuver, typically caused by orbital debris on the ISS' path. In addition to trajectory adjustments overseen by the Trajectory Operations Officer (TOPO), the solar arrays must be locked, thus reducing power generation, managed by the Power Heating and Lighting Control Officer (PHALCON). If this situation persists, some powered payload or crew activities may have to be delayed by the Ops Controller (Ops) until there is enough power. If there was an Extra-Vehicular Activity (EVA) scheduled, its related activities may have to be adjusted, and so on.

The "Automation for Operations" (A4O) project at NASA develops advanced automation technology for infusion into human space-flight mission operations. As part of this project, we have created distinct planning software applications that support the Ops and PHALCON disciplines, as well as collaborative planning between them. These applications map naturally to the current discipline boundaries and collaboration model. Present day operations involve coordination between PHALCON and Ops controllers by a combination of voice loops, manual plan modification and validation, and manual integration of plan changes between disciplines. Our advanced prototype improves on the state of the art in several ways. First, by enabling the flight controllers to use automation to rapidly modify plans, flight controllers gain flexibility and improved responsiveness to unpredictable events during operations. Second, by employing model-based planning technology, operational tools can be modified more efficiently as the rules change (a frequent occurrence due to changes in equipment configuration and flight software). Finally, by providing tools that seamlessly transmit information between disciplines, coordination between flight controllers is simplified, thereby decreasing conflict on voice loops and streamlining the operations process. 


\begin{tabular}{|c|c|}
\hline Discipline & Brief Description \\
\hline Flight Director (Flight) & $\begin{array}{l}\text { Primary decision-making authority for station operations. Leads flight } \\
\text { control team. }\end{array}$ \\
\hline $\begin{array}{l}\text { Assembly and Checkout } \\
\text { Officer (ACO) }\end{array}$ & $\begin{array}{l}\text { Integration of assembly and activation tasks for all ISS systems and } \\
\text { elements. }\end{array}$ \\
\hline $\begin{array}{l}\text { Attitude Determination and } \\
\text { Control Officer (ADCO) }\end{array}$ & $\begin{array}{l}\text { Works in partnership with Russian controllers to manage the station's } \\
\text { orientation. controlled by the onboard Motion Control Systems. Calculates } \\
\text { future orientations and manewwers for the station. }\end{array}$ \\
\hline $\begin{array}{l}\text { Communication and } \\
\text { Tracking Officer (CATO) }\end{array}$ & $\begin{array}{l}\text { Management and operations of the U.S. communication systems, } \\
\text { including audio, video, telemetry and commanding systems. }\end{array}$ \\
\hline $\begin{array}{l}\text { Environmental Control and } \\
\text { Life Support System } \\
\text { (ECLSS) }\end{array}$ & $\begin{array}{l}\text { Responsible for the assembly and operation of systems related to } \\
\text { atmosphere control and supply, atmosphere revitalization, cabin air } \\
\text { temperature and humidity control, among other areas. }\end{array}$ \\
\hline $\begin{array}{l}\text { Extravehicular Activity } \\
\text { Officer (EVA) }\end{array}$ & $\begin{array}{l}\text { Responsible for all spacesuit and spacewalking-related tasks, equipment } \\
\text { and plans. }\end{array}$ \\
\hline $\begin{array}{l}\text { Onboard, Data, Interfaces } \\
\text { and Networks (ODIN) }\end{array}$ & $\begin{array}{l}\text { Responsible for the U.S. Command and Data Handling System, including } \\
\text { hardware, software, networks, and interfaces with International Partner } \\
\text { avionics systems. }\end{array}$ \\
\hline $\begin{array}{l}\text { Operations Support Officer } \\
\text { (OSO) }\end{array}$ & $\begin{array}{l}\text { Console operator that is charged with those logistics support functions that } \\
\text { address on-orbit maintenance, support data and documentation, logistics } \\
\text { information systems, maintenance data collection and maintenance } \\
\text { analysis. }\end{array}$ \\
\hline $\begin{array}{l}\text { Power, Heating, Articulation, } \\
\text { Lighting Control Officer } \\
\text { (PHALCON) }\end{array}$ & $\begin{array}{l}\text { Manages the power generation, storage, and power distribution } \\
\text { capabilities. }\end{array}$ \\
\hline $\begin{array}{l}\text { Robotics Operations } \\
\text { Systems Officer (ROSO) }\end{array}$ & $\begin{array}{l}\text { Responsible for the operations of the Canadian Mobile Servicing System, } \\
\text { which includes a mobile base system, station robotic arm, station robotic } \\
\text { hand or special purpose dexterous manipulator. }\end{array}$ \\
\hline $\begin{array}{l}\text { Thermal Operations and } \\
\text { Resources (THOR) }\end{array}$ & $\begin{array}{l}\text { Responsible for the assembly and operation of multiple station } \\
\text { subsystems which collect, distribute, and reject waste heat from critical } \\
\text { equipment and payloads. }\end{array}$ \\
\hline $\begin{array}{l}\text { Trajectory Operations } \\
\text { Officer (TOPO) }\end{array}$ & $\begin{array}{l}\text { Responsible for the station trajectory. The TOPO works in partnership with } \\
\text { Russian controllers, ADCO, and the U.S. Space Command to maintain } \\
\text { data regarding the station's orbital position. TOPO plans all station orbital } \\
\text { maneuvers. }\end{array}$ \\
\hline Operations Planner (Ops) & $\begin{array}{l}\text { Leads the coordination, development and maintenance of the station's } \\
\text { short term plan, including crew and ground activities. }\end{array}$ \\
\hline Ground Controller & $\begin{array}{l}\text { Responsible for MCC systems and coordination with the ground to space } \\
\text { communications network. }\end{array}$ \\
\hline
\end{tabular}

\section{Figure 1. ISS Mission Control Disciplines}

Collaboration is enabled by an architecture developed specifically for coordinating disparate planning systems. This architecture provides translation and synchronization mechanisms that allow the automated planners for each discipline to use different planning technologies and be as complex and domain-specific as necessary. Specifically, the planners may each use different domain models and representations, but may still communicate essential state and intention with others. As a result, automated planners are given access to information that is necessary in making decisions for their discipline, but may be owned by other disciplines.

Planning ISS operations is a highly collaborative process that requires numerous iterations and negotiation among the NASA disciplines and with International Partners (IPs). The current approach is already putting great demands in terms of training and time needed to generate and coordinate plans on the human planners, automation is greatly needed to alleviate their burden.

The paper organization is as follows: first, we describe the domain requirements for both the Ops and PHALCON disciplines, and the planning applications developed to address their needs. Next, we describe at a domain level, a scenario that requires collaboration between the 2 disciplines, then we describe how this collaboration was implemented using the $\mathrm{A} 4 \mathrm{O}$ architecture. We conclude by pointing out current and future directions for this work.

\section{Crew PlanNing}

The Station Ops Planner leads the coordination, development and maintenance of the station's short-term plan, including crew and ground activities. The plan includes the production and uplink of the On-Board Short Term Plan (OSTP) and the coordination and maintenance of the on-board inventory and stowage listings. Planning for an ISS increment (the time period a specific crew remains on the ISS) is done in several iterations with an increasing degree of granularity : 


\begin{tabular}{|l|l|l|}
\hline \multicolumn{1}{|c|}{ Product } & \multicolumn{1}{|c|}{ Description } & \multicolumn{1}{c|}{ Timing } \\
\hline $\begin{array}{l}\text { Ground Rules and } \\
\text { Constraints (GR\&C) }\end{array}$ & $\begin{array}{l}\text { First effort to respond to the } \\
\text { priorities outlined for the } \\
\text { increment }\end{array}$ & $\begin{array}{l}\text { Development starts 8 } \\
\text { months before the } \\
\text { increment }\end{array}$ \\
\hline $\begin{array}{l}\text { On-Orbit operations } \\
\text { summary (OOS) }\end{array}$ & $\begin{array}{l}\text { First plan to address priorities for } \\
\text { the increment. Covers entire } \\
\text { increment }\end{array}$ & $\begin{array}{l}\text { Development starts 5.5 } \\
\text { months before the } \\
\text { increment }\end{array}$ \\
\hline $\begin{array}{l}\text { Weekly Lookahead plan } \\
\text { WLP) }\end{array}$ & $\begin{array}{l}\text { More realistic representation of } \\
\text { the OOS, more detailed } \\
\text { constraint modeling }\end{array}$ & $\begin{array}{l}\text { Generated 3 weeks } \\
\text { before the increment's } \\
\text { day is executed }\end{array}$ \\
\hline Short Term Plan (STP) & $\begin{array}{l}\text { More realistic constraint } \\
\text { modeling. Intructions ofr } \\
\text { execution are included }\end{array}$ & $\begin{array}{l}\text { Generated 2 weeks } \\
\text { before the increment's } \\
\text { day is executed }\end{array}$ \\
\hline $\begin{array}{l}\text { On-Board Short Term } \\
\text { Plan (OSTP) }\end{array}$ & $\begin{array}{l}\text { This is the plan that is uplinked to } \\
\text { the ISS and executed }\end{array}$ & $\begin{array}{l}\text { Generated 1 week } \\
\text { before the increment's } \\
\text { day is executed }\end{array}$ \\
\hline
\end{tabular}

Figure 2. Planning products for an ISS increment

The crew will typically stay as close as possible to the OSTP, although unforeseen repairs, medical procedures and other similar urgent conditions normally arise during each increment. Any changes to the OSTP are handled through a Planning Product Change Request (PPCR), which requires approval of at least 3 people.

For our tests we concentrated on the OSTP, but the same approach can be used to support the other time intervals.

\section{ACTIVITIES AND CONSTRAINTS}

All of the activities and constraints for the increment are documented in detail in the GR\&C and other supporting documents that provide payload and other, discipline-specific details [3], a very brief summary of the most important elements for Crew Planning is provided below.

- The crew plan has a stable backbone in the form of a pattern that repeats daily : the day starts with a post-sleep period which lasts 90 minutes and includes personal time, breakfast and preparation for the day. Next is the daily planning conference (DPC) which takes about 15 minutes, this is a brief conversation with mission control to go over the plan for the day. In the middle of the day there is a 1 hour block for lunch, which is taken together by the crew if possible. At the end of the day there is a pre-sleep period of 120 minutes that includes debriefing for the day, dinner and personal time. The day ends with a 8.5-hour sleep period. Given the negative effects of low-gravity on the human body, crew members are required to exercise for 2.5 hours every day. There are several pieces of exercise equipment on board and each crew member has some latitude to choose the kind of exercise, time of the day and intervals (a single block vs. 2 separate sessions).

- Beyond the daily pattern, there are a number of activities that repeat more or less regularly, like medical conferences and some maintenance activities.

- Many payload activities (science experiments) require involvement from the crew and also entail some temporal and resource constraints, including power.

- There are complex procedures for certain maintenance or repair operations and for EVAs (space walks). These typically contain a number of sub-activities with associated temporal and resource constraints.

- When a spacecraft (shuttle, soyuz) is docked to the ISS, joint operations with the visiting crew require a temporary change of structure (ISS may have to work in shifts for a while to provide around-the-clock coverage). There are also a number of complex procedures (docking, undocking, joint EVAs and others) that are associated with this mode of operation.

\section{PLANNING GOALS}

The main goals are safety and feasibility. Ops planners want to always have plans that are executable and that do not violate any of the medical or procedural constraints. 
The other major objective is to maintain a good quality of life for the crew. This involves things like stability of the schedule, respect of crew rest periods, exercise equipment preferences, and personal time. In addition to the previous objectives, it is desirable to achieve as many science goals as possible within each increment.

Changes in the power profile can potentially affect any of the crew activities, however, the Ops planners only need to know a summarized profile (for discrete named power levels, how much power is available and for how long), whereas the detailed computation and management of power is the responsibility of the PHALCONs, which is where we turn our attention next.

\section{Power Planning}

The Power Planning responsibility within the PHALCON discipline is charged with managing the generation, conditioning and supply of power to the ISS (the Provide Power function), as well as coordinating the reconfiguration of the electrical power system (the Control EPS function). Matching the planning focus of the crew planner, our tests concentrate on the OSTP horizon of about a week in advance, where dynamic planning is most relevant.

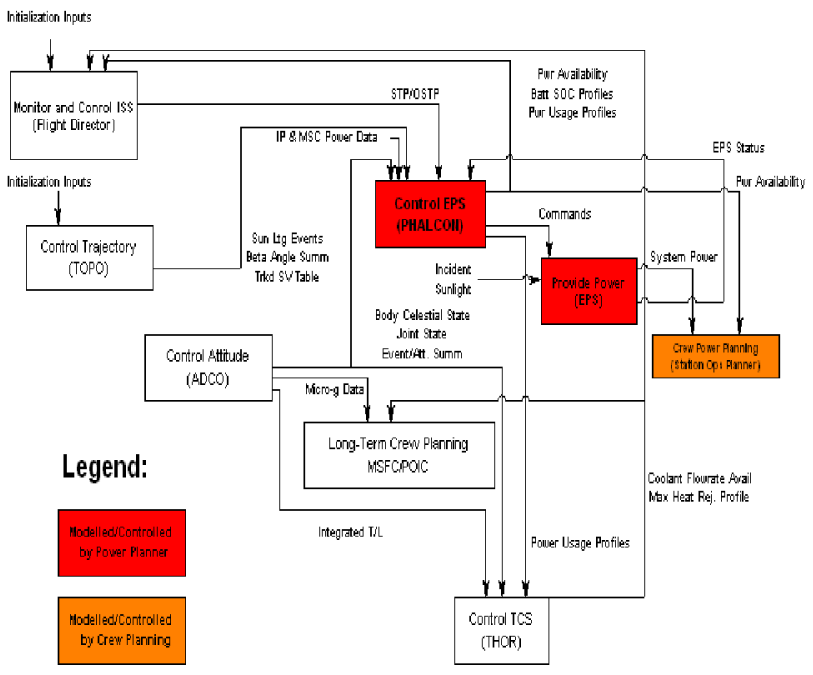

Figure 3. Power Planning function in Context

The main source of control inputs to Power Planning is the Attitude Control discipline (ADCO). ADCO provides constraints on station attitude as well as array pointing angles, which directly affect the available power generation. From this varying supply, the power plan must choose how to serve the various power loads scheduled in the Flight Director's consolidated plan (which includes Crew Planning inputs along with contingency activities). Excess supply may be stored to (and excess load may be drawn from) the station's battery array, within hardware and flight rule constraints. The interaction of Power Planning with other disciplines is summarized in Figure 4.

\begin{tabular}{|c|c|c|c|}
\hline & Item & To / From & Description \\
\hline Inputs & Incident Sunlight & Sun & Dreect suniglt on solar arrays. \\
\hline \multirow{9}{*}{ Control Data } & IP \& MSC Power Data & PRO/PHALCON & Trending ditot for fiture planning \\
\hline & STP/OSTP & Flight Director & $\begin{array}{l}\text { Long-Terrm activity profles tor baseling } \\
\text { phenring. }\end{array}$ \\
\hline & Body/Celestial State & ADCO & Station attiucte and ephemeris. \\
\hline & Sun Lighting Events & ADCO & Dary Night on ISS as a fundton of orbit. \\
\hline & Beta Angle Summmary & ADCO & Solir Eeta Angles st ISS \\
\hline & State Variable Table & ADCO & Ephements tor ISS \\
\hline & Joint State & ADCO & Solar Array Jirit angles \\
\hline & Event/Attitude Summary & $\mathrm{ADCO}$ & 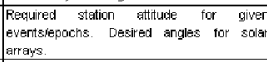 \\
\hline & EPS Status & EPS & Telemetry frow power generationiconditioning \\
\hline \multirow{5}{*}{ Outputs } & Power Availability & $\begin{array}{l}\text { Flight Director, Crew } \\
\text { Power Planning }\end{array}$ & Current BEse Supply \\
\hline & Battery SOC Profiles & Flight Director & Prolectted bittery Soc based on flan \\
\hline & Power Usage Profiles & Flight Director & 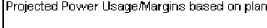 \\
\hline & Commands & EPS & Commends to control the EPS \\
\hline & System Power & Crew Power Planning & Condtioned power to crew loads \\
\hline
\end{tabular}


Figure 4. Power Planner Interfaces and Descriptions

\section{ACTIVITIES AND CONSTRAINTS}

The backbone power plan consists of a periodic response to changing solar availability. In station orbit, the sun rises every 92 minutes and illuminates the station for approximately 60 minutes at constantly changing angles. In order to maximize the power generation from the solar arrays, the array assemblies are placed in an auto-track mode when the sun is visible. When the station enters eclipse, the arrays are stowed to a drag-reduction bearing. This diminishes the atmospheric drag on the station and saves on re-boosts by the shuttle. During the eclipse periods, the station operates fully from the energy stored in its battery array. The battery's state of charge is tracked in detail as a metric resource. When the sun rises once more, the arrays are again steered to auto-track the sun and power generation resumes.

Crew and station operations are layered on top of this periodic plan, and may force the arrays to be configured in a mode contrary to backbone. For example, the array steering must be locked out during extra-vehicular (EVA) maintenance of the station for the safety of the astronauts. Each possible contingency activity is modeled along with its array pointing requirements, and the array mode is tracked as a state variable of the system. Transition Activities are taken by the power planner to effect any of the legal mode transitions and reconfigure the solar arrays as appropriate to the specific situation. Prime activities and the transition matrix are presented in Figure 5.

The power plan may also explicitly call for load shedding on the station's EPS. This occurs if the battery reserves fall below a flight-rule constraint, and ensures that the station and crew have ample power in case of emergency. The current constraint is approximately $85 \%$ of the battery's full state of charge. After the battery reserves have been replenished, the power plan can call for previously shed loads to be reinstated.

\section{PLANNING GOALS}

Safety and survivability are the primary goals of the power plan. The power plan must at all times maintain an emergency margin to protect the crew in the event of a station failure. A secondary objective is to fully supply all of the station experiments and extraneous loads, and also to reduce aerodynamic drag of the station.

Station operational goals (EVAs, collision avoidances, water dumps, etc) are mandated to the power planner, which in turn publishes a power profile summary to other disciplines. This summary includes a named power mode indicating the level of support offered by the EPS for each time period within the plan horizon. 

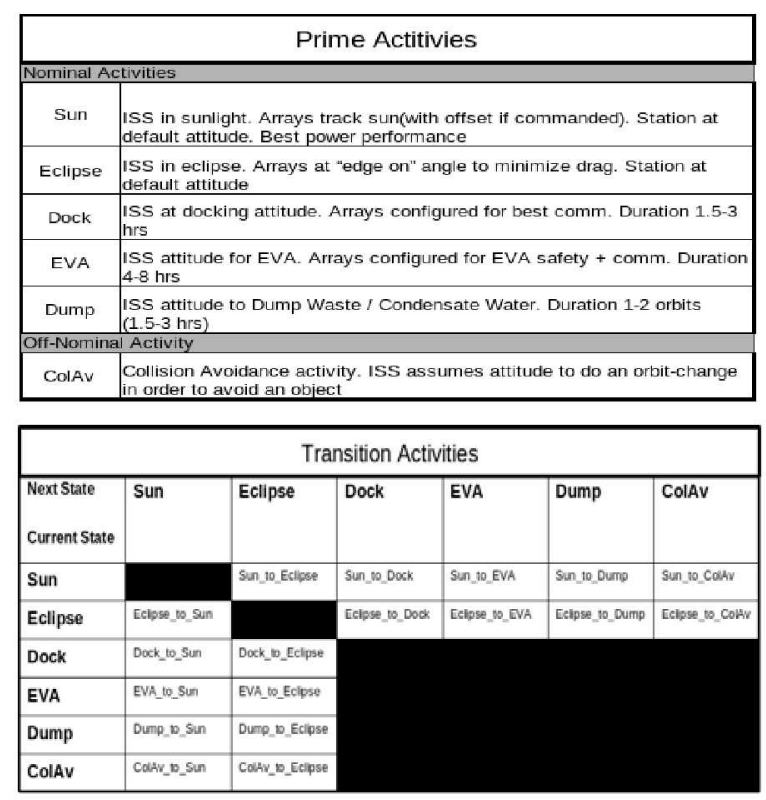

Figure 5. Planner Prime Activities and Transition Activity Matrix

\section{INTER-DISCIPLINE INTEGRATION SCENARIO}

As can be seen from the descriptions above, understanding and modeling each discipline requires a considerable amount of effort. After the discipline-specific domain models are in place, we are ready to dive into interactions between them.

Changes introduced by PHALCON will typically affect many of the other disciplines, in fact, this was one important reason to include that discipline in our tests. On the Crew Planning side, most activities do not consume enough power to warrant power planning consideration when they are changed. However there are some exceptions, such as the operation of the robotic arm. Other activities that may trigger reaction from PHALCONs, are activities that limit power production, such as collision avoidance maneuvers and water dumps, which require the solar arrays to be locked to protect them from damage.

In our scenario, a water dump is part of the nominal plan (OSTP), however, it is not uncommon for this activity to take longer than expected since the evacuation rate may vary. If a water dump activity is extended beyond its original duration, it is normally extended for at least the duration of one orbit (92 minutes), during this time the solar arrays are locked to prevent damage. On the power side, one of the flight rules is to maintain the battery levels to at least $85 \%$ capacity; whenever the battery is drained below that level, the EPS switches from nominal mode to what is called "core" mode, and power for some non-essential sub-systems may be interrupted until the battery goes back above the required charge level. 


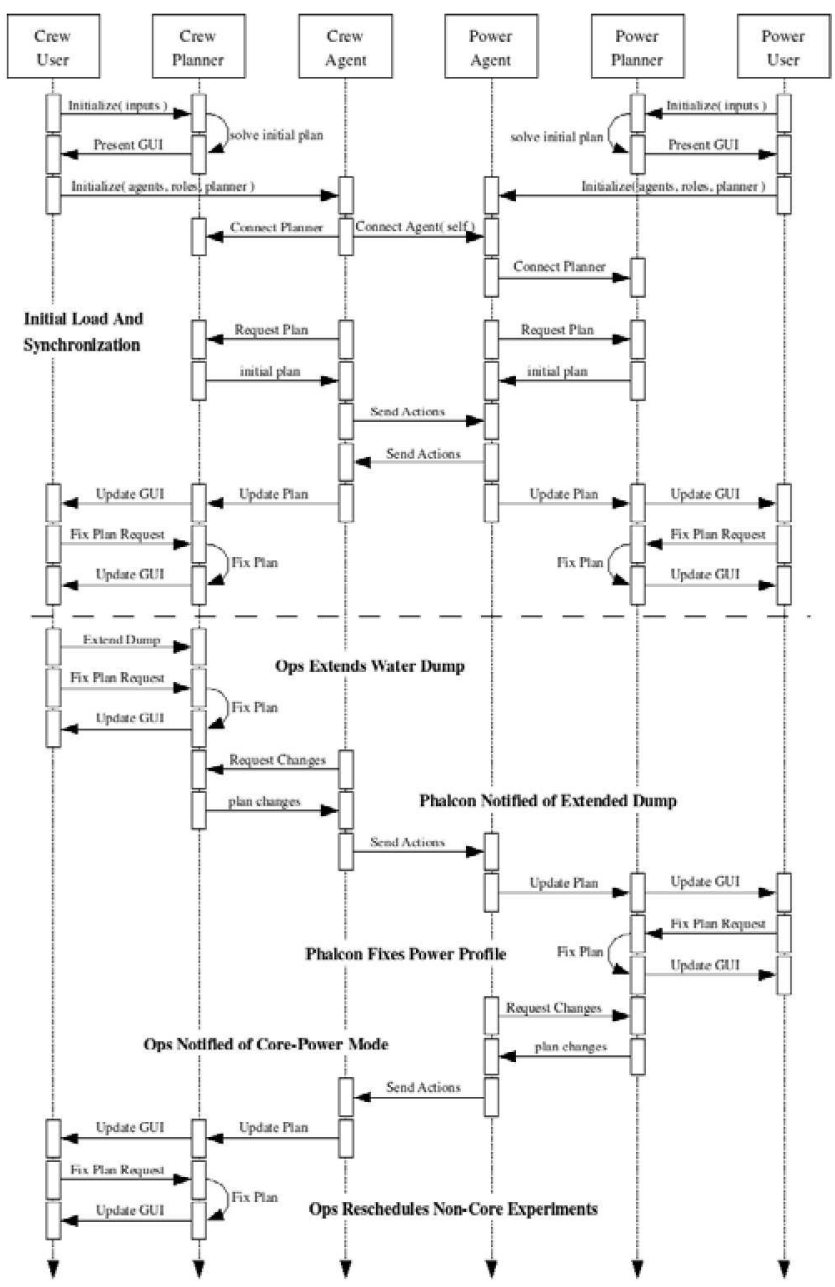

Figure 6. Inter-discipline integration scenario

To test communication initiated from the Crew planner we extend the duration of a water dump activity in the crew plan. (See Figure 6) The power planner receives the new information and flags the possible violation of the minimum $85 \%$ battery level given the new duration. The PHALCON controller is then able to rely on the Power planner to automatically fix the plan for the solar arrays and produce the new power profile.

However, the new situation cannot be handled without going into core mode for a short period of time. This change is propagated to the crew planner, where some of the science payload activities are on a power string that is disabled when the EPS enters core mode. This causes the Ops controller to see conflicts on the activities planned for the crew. The controller may in turn rely on the automated Crew Planner to fix the problems, or do it manually.

In our scenario we stop at this point with consistent plans on both planners, but the coordination could continue, especially if other disciplines are involved. This process is currently performed with some IT support, but without any significant planning and scheduling technology. The visibility and agility provided by the automated planners should be of great benefit to the controllers.

\section{ARCHITECTURE FOR AN INTEGRATED SOLUTION}

A collaboration infrastructure was developed to allow for the efficient exchange of essential plan information among the disparate discipline-specific planning engines. A coordination agent is externally attached to each participating planner (see Figure 7), and each agent is concisely configured to translate events between the planner it represents and the other coordination agents it connects to. The coordination scheme owes a philosophical heritage to the ShAC multi-agent 
coordination system [4], but was redeveloped from the beginning to support various planning architectures for the agents. In particular, the exchanged plan entities do not themselves describe how an action or resource is to be considered, just that it exists with specific values. The separate domain planners decide independently how to interpret and act on the information. For example, a PHALCON controller will consider the details of a solar array maneuver and its effect on generated power, but the EVA controller need only be assured that the arrays are locked during a spacewalk.

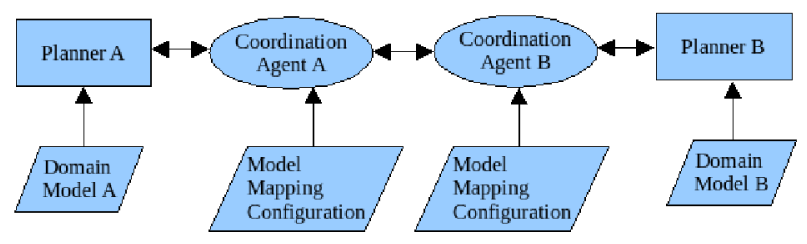

Figure 7. Coordination Architecture

This separation of system expertise has several benefits :

- It directly reflects the administrative divisions of the humans using the aggregate system.

- Specific domain models are much easier for experts to articulate, and thus encode within a planning system of choice.

- A different planning tool can be used for each domain.

- The problem size for each domain is considerably smaller than if all constraints were considered within a single planning context.

The division of expertise comes with costs however. The most notable is handling communication among different agents when coordinated action is called for. Fortunately, as in many domains, the ISS utilizes fairly coarse-grained coordination, and thus communication cost is limited to a small set of mission-wide actions.

The set of actions that a cognizant discipline controller publishes, as well as those external actions it needs to coordinate on, are listed in a small file that describes the mapping of identifiers used by each agent. The collaboration infrastructure uses this mapping to generate just those updates that are needed to maintain the consistency of the aggregate system. Possible updates include creation, deletion, and modification of planned actions. These updates are sent to agents that are interested in the subject action. Resource and timeline changes are propagated via coordinated value modification actions.

Note that the details sent to each agent depend on their use of the action/resource: the PHALCON controller has full watthour detail on every power draw, but the Ops system only gets updates when the power system expects switches between "core" and "nominal" modes. 


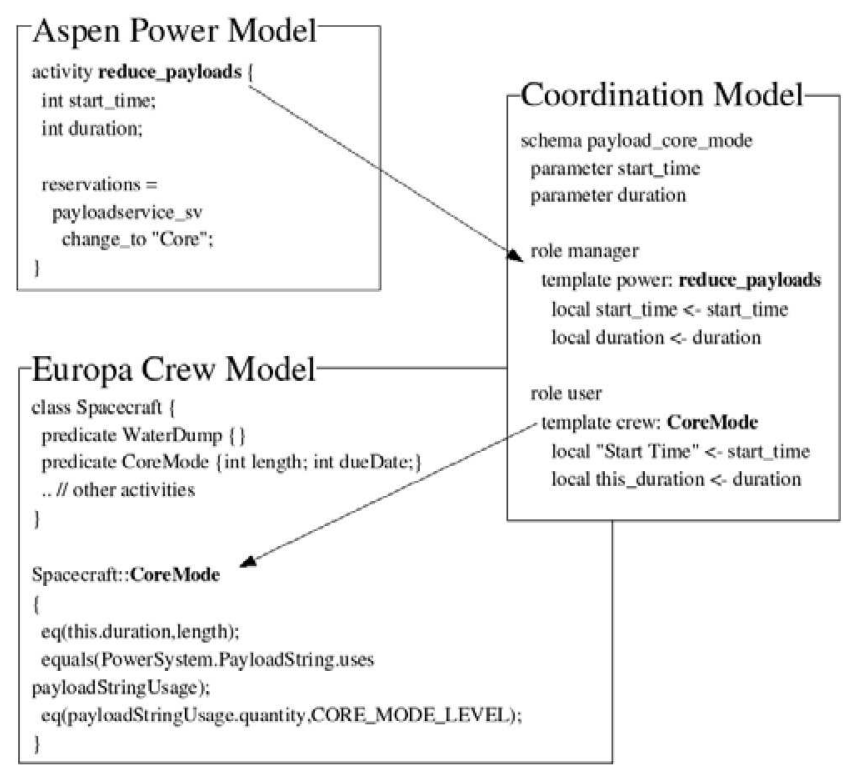

Figure 8. Model mapping in the Coordination Agent

The mapping language for the coordination agent is presented in Figure 8. The "Coordination Model" box contains a snippet from our demonstration that includes all the elements in the language. A schema element describes a specific part of the domain models that must be synchronized, in this example, the "reduce payloads" activity in the Power domain will be represented by corresponding "CoreMode" activities in the Crew domain. Each schema element contains role and parameter elements. Possible planner roles are manager (if the planner publishes information) or user (if the planner consumes information). Each schema element must contain at least one manager role and one or more user roles. Each role element contains template and local elements. The template element specifies the name of the planner, and the activity type to be synchronized, in our example, the element "template power:reduced payloads" means that for the planner called "power" we will monitor instances of the activity type "reduced payloads". Finally, the parameter element from schema and the local element from role provide a mechanism to specify how activity parameters are mapped from one domain to another.

The Coordination Agent reads this description and uses CORBA to communicate with the planner it represents before the other Coordination Agents. Each planner must therefore support a small CORBA interface and register with the CORBA naming service using the same name specified in the template element described above.

The CORBA interface contains only 4 methods (method signatures are abstracted for brevity's sake) :

- getChanges 0 : Returns a data structure specifying all activities added/deleted/changed inside the planner since the last time this method was called. This is used by the coordination agent to get changes from the planner and push them out to other interested coordination agents.

- add/delete/changeActivities(Collection<Activity> acts) : these 3 methods are used by the coordination agent to push changes coming from other coordination agents into the planner.

A common agent code base sits on top of this CORBA interface and manages all of the planner's coordination. Thus the planners themselves need not have any concept of coordination.

As can be seen in Figure 8, the Coordination Model maps directly to elements inside each of the domain models. The coordination mechanism although complete is not very flexible in terms of mapping different semantics or data granularity levels. For this approach to work correctly and efficiently it is important to write domain models that are amenable to it. Currently we take advantage of the sophisticated modeling mechanisms available in both EUROPA and ASPEN to provide appropriate placeholders for coordination (this takes care of semantic differences) and to aggregate/disaggregate activity information from each domain model (this takes care of data granularity differences). Fortunately, this is natural thing to do 
since currently the human planners perform similar kinds of operations in order to be able to talk to other disciplines. However, in terms of implementation, this functionality could eventually be part of the coordination agents to keep the models free of elements needed only for coordination purposes.

Finally, unlike the ShAC system, our current demonstration does not utilize any structured coordination protocols, instead each agent simply notifies the others of updates it has affected. Ownership of modeled actions is reflected directly in the domain models of each discipline (eg the power controller simply does not have permission to add crew sleep activities). In expanded systems, this peer-to-peer interaction is expected to be replaced with protocols akin to ShAC's master-slave or round-robin rights dispatching.

\section{IMPLEMENTATION}

Crew and Power planning applications were created using EUROPA and ASPEN, two different planning platforms developed at NASA, whose respective strengths matched well with their assigned domain. The coordination architecture was implemented in C++ and CORBA was used as the middle-ware for inter-process communication. The solution was deployed and demonstrated on Linux workstations.

This implementation was used to automatically generate an OSTP to cover 4 days of operation for a 3-member crew, using information about payloads and activities from a previous ISS increment. Two way communication between the planners was demonstrated by manipulating activities in both planners and using the other planner to automatically flag new problems in the plan and assist the corresponding discipline in solving them. The entire system was validated in demonstrations at NASA's Johnson Space Center given to controllers from both disciplines. The controllers commented favorably on the system's applicability and expressed support to continue to develop this approach to cover more of the planning process.

\section{CREW PLANNING APPLICATION}

The Crew Planning application was created using Ensemble [5] for the UI and EUROPA [6,7] as the planning engine. This same combination is already being used in several NASA missions such as MER and Phoenix [8].

The Crew Planning model includes all of the main domain elements outlined above (daily plan backbone, medical conferences, maintenance and payload activities). The Power Profile is visualized as a high-level timeline that only contains "core" and "nominal" states.

The user can manipulate the plan by adding, changing and removing activities. The planning engine provides constraint checking, constraint violation explanation and automated conflict resolution for a number of temporal and resource constraints. 


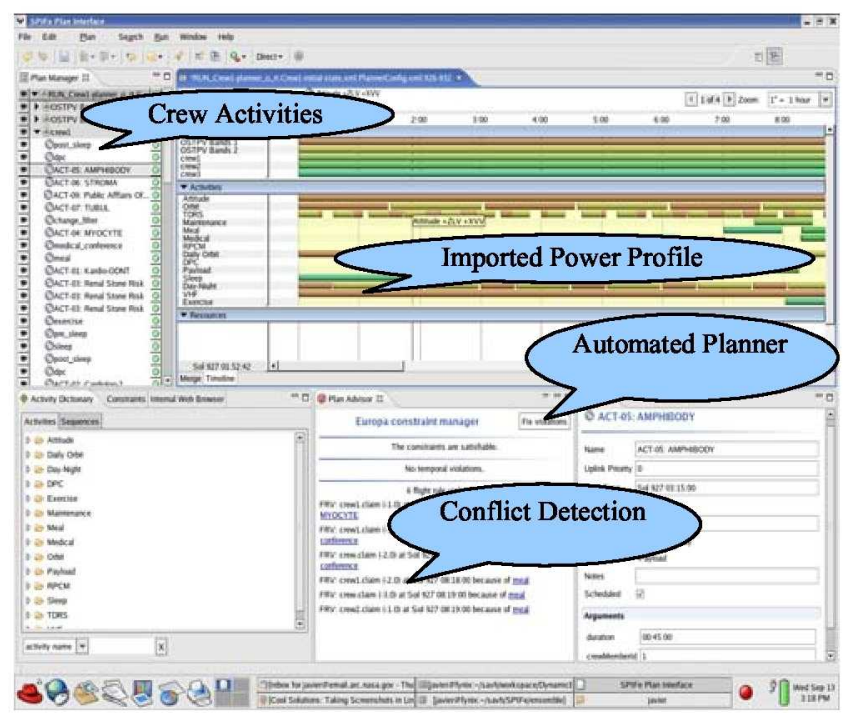

Figure 9. Crew Planning Application

\section{POWER PLANNING APPLICATION}

The ASPEN [9] general automated planning system was used to provide power discipline planning. ASPEN has been used by several missions for ground-based operations planning, as well flown on board for real-time planning capabilities $[10,11]$. The ASPEN system uses a custom JAVA-based GUI interface to facilitate human interaction with the automated planner.

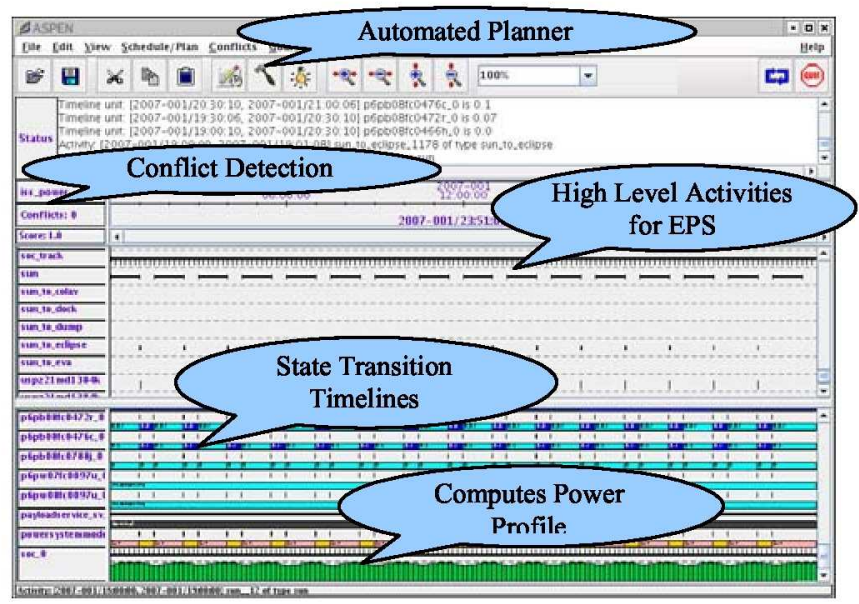

Figure 10. Power Planning Application

The power discipline model is encoded in a textual input file, and is developed by consulting both human experts and ISS procedure documentation. The plan domain includes treatment of exogenous sunrise and sunset events, crew-initiated station maneuvers, battery and bus resource monitoring, and generates appropriate power system command actions to steer the solar arrays and manage dynamic EPS loads. The plan is presented to the user in Gantt-chart summary form, from which they may inspect the solution, examine plan conflicts, hand tweak event timing and resource usages, and call upon the automated planning engine to assist. 


\section{CONCLUSIONS AND FUTURE DIRECTIONS}

Generating an ISS increment plan is a highly collaborative process that requires numerous iterations and negotiation among the NASA disciplines as well as with international partners to converge to a consistent plan. The current tools to support this process leave a lot of the burden of constraint checking, contingency evaluation, optimization and integration to the human planners. This is already an overwhelming burden $[12,13]$ and it will only get worse as the ISS grows and the role of international partners becomes increasingly prominent. The training and communication costs, as well as time delays make it very hard to scale up the current process to continue to do increment planning as the ISS grows and other missions need to be supported by the same personnel.

We have demonstrated how a significant part of this burden can be transferred to automated planning tools in a way that supports the organizational boundaries and expertise that are currently in place. We have created detailed applications to support the Ops and PHALCON disciplines and have demonstrated through a realistic scenario how required communication between the two can be carried out. The integration architecture and approach is domain-independent and can be scaled up to support any number of disciplines, so that it could eventually used to support the entire planning process.

There are numerous avenues that can be pursued to build on this work and improve support for space mission planning and control, below we list some of the most promising ones (some of these are already being actively pursued by the same team):

- Evaluation of alternative plans would be very useful. Our application only allows for coordination of a single plan. Out entire infrastructure (EUROPA, ASPEN, and the integration architecture) allows for the manipulation of multiple plans, but this capability needs to be exposed at the application level to the end user.

- Integration with Procedure Execution and real time telemetry would be a great addition to support real-time re-planning.

- At the application level, better support for negotiation would be very useful, examples of this are better notification and explanation of events coming from other disciplines, logging of negotiation decisions and iterations, etc.

\section{ACKNOWLEDGMENTS}

This work was performed at Ames Research Center and at the Jet Propulsion Laboratory, California Institute of Technology, under contract with the National Aeronautics and Space Administration. Many thanks to Joseph Breno, James Solomon and Kevin DePaola at Johnson Spaceflight Center for sharing their domain expertise, and to Jeremy Frank at NASA Ames for his insightful comments on an early draft.

\section{REFERENCES}

[1] Freed M., et al. 2005. Trusted Autonomy for Spaceflight Systems, in Proceedings of the 1st Space Exploration Conference: Continuing the Voyage of Discovery.

[2] http://www.shuttlepresskit.com

[3] NASA, ESA, JAXA, CSA. 2006. Generic Ground Rules, Requirements, and Constraints. International Space Station Program.

[4] Clement B., Durfee E., Barrett A. 2007. Abstract Reasoning for Planning and Coordination. Journal of Artificial Intelligence Research (JAIR), volume 28.

[5] Michael McCurdy, Guy Pyrzak, Christian Ratterman, Alonso Vera, "The Design of Efficient Ground Software Tools. 2006. In 2nd IEEE International Conference on Space Mission Challenges for Information Technology (SMC-IT'06)

[6] Frank, J., and Jonsson, A. 2003. Constraint-based attributes and interval planning. J. Constraints 8.

[7] https://babelfish.arc.nasa.gov/trac/europa 
[8] A. Aghevli, A. Bachmann, J. Bresina, K. Greene, B. Kanefsky, J. Kurien, M. McCurdy, P. Morris, G. Pyrzak, C. Ratterman, A. Vera, and S. Wragg. Planning Applications for Three Mars Missions with Ensemble. 2006. In International Workshop on Planning and Scheduling for Space

[9] S. Chien, G. Rabideau, R. Knight, R. Sherwood, B. Engelhardt, D. Mutz, T. Estlin, B. Smith, F. Fisher, T. Barrett, G. Stebbins, D. Tran. 2000. ASPEN - Automating Space Mission Operations using Automated Planning and Scheduling in International Conference on Space Operations (SpaceOps 2000)

[10] R. Sherwood, S. Chien, D. Tran, B. Cichy, R. Castano, A. Davies, G. Rabideau. 2007. The EO-1 Autonomous Sciencecraft. Small Satellite Conference.

[11] Clement B., Johnston M.. 2006. Design of a Deep Space Scheduling System. International Workshop on Planning and Scheduling for Space (IWPSS 2006).

[12] Schauer C., Sylver B. 2007. Misdiagnosed: The Story of how NASA's International Space Station Planning Team Thought They Needed a Collaboration Tool to Solve Their Problems When What They Really Needed was Better Planning Tools. ICAPS '07 Workshop.

[13] Korth D., LeBlanc T. 2002. International Space Station Alpha Operations Planning. Proceedings of the International Workshop on Planning and Scheduling for Space.

\section{BIOGRAPHY}

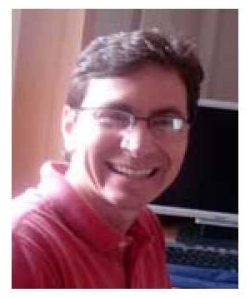

\begin{abstract}
Javier Barreiro is a Computer Scientist

with SGT

Inc. at the

NASA Ames Research Center. He leads the development of EUROPA, a platform for the development of Planning, Scheduling and Constraint Programming applications. He is also the lead for the decision support group of the "Automation for Operations" project. His main interests are Discrete Optimization, Constraint Programming, Planning and Scheduling. He holds an M.E. in Operations research from the University of Texas at Austin, an M.S. in Computer Science from Rensselaer Polytechnic Institute and B.S. degrees in Computer and Industrial Engineering from the University of Los Andes in Bogota, Colombia.
\end{abstract}

Grailing Jones Jr. is a Technical

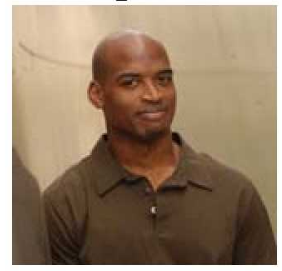

Staff member in the Flight

Engineering Group at the Jet 
Propulsion Laboratory. He has evaluated, developed and operated mission planning and execution systems for a variety of NASA and DOD projects. He earned his B.S. in Astronautics from the United States Air Force Academy and Masters in Aerospace Engineering from the University of Colorado at Boulder.

Steve Schaffer is a research programmer at NASA's Jet Propulsion Laboratory, where he is a member of the Artificial Intelligence Group. He has worked on a variety of AI applications, including on-board rover autonomy, deep space antenna scheduling and control, sensorweb architectures, multi-agent plan coordination, and autonomous planning under uncertainty. His general research interests are in heterogeneous multiagency, adaptive algorithms, and reasoning under uncertainty. Steve graduated with bachelor's degrees in computer science and chemistry from Carnegie Mellon University, and is a current master's student in computer science at the University of Southern California. 